\title{
Traços da cristologia narrativa de Schillebeeckx
}

\section{Traits of Schillebeeckx Narrative Christology}

\section{Valdete Guimarães*}

\section{RESUMO}

O presente artigo apresenta uma reflexão sobre a cristologia narrativa de Schillebeeckx, com enfoque na experiência que os discípulos fizeram da ressurreição de Jesus. O acento na experiência Pascal acontece por esta temática se apresentar como pedra de toque da reflexão schillebeeckxiana na busca da reconstrução da experiência originária da fé a fim de que possa iluminar ainda hoje outras experiências que poderão ser realizadas com o ressuscitado. Neste sentido, a categoria da experiência aparece como pano de fundo de toda a abordagem, já que a experiência constitui o instrumental teórico de interpretação para a reflexão cristológica do autor.

Palavras-chave: Jesus. Cristologia. Narrativa. Experiência. Ressurreição.

\section{ABSTRACT}

The article presents a reflection about narrative Christology of Schillebeeckx, the principal approach it's on what the disciples did on the Jesus resurrection. The emphasis on the Pascal experience happens because of this theme is the touchstone of the schillebeeckxian reflection in the search for the reconstruction of the original experience of the faith so that it can still illuminate other experiences that can be realized with the resurrected one. In this way, the category of experience appears as the background of the whole approach, seeing experience appoint the theoretical instrument of rendering for the authors Christological reflection.

Keywords: Jesus. Christology. Experience. Rresurrection.

\footnotetext{
* Licenciada em Filosofia (PUC-PR); Graduada em Teologia (FAJE-BH); Mestra em teologia (FAJE-BH); Doutora em Teologia (FAJE-BH). Professora de Teologia na Faculdade Diocesana São José (FADISI) - Rio Branco/AC. <valdeteguimaraes.sc@gmail.com>
} 


\section{INTRODUÇÃO}

$\mathrm{O}$ artigo visa mostrar traços da cristologia narrativa de Schillebeeckx, tendo como horizonte a categoria da experiência. Deste modo, se propõe a fazer uma correlação crítica entre a experiência dos primeiros discípulos, que nos é relatada pelo Evangelho, e as experiências realizadas por homens e mulheres contemporâneos.

Schillebeeckx adverte que na origem do cristianismo "há uma experiência bem precisa" Jesus de Nazaré, que os motivou a uma verdadeira regeneração de vida, concedendo-lhes uma nova identidade. $\mathrm{O}$ "novo ser" dos discípulos se expressa justamente no entusiasmo pelo anúncio do Reino e pela solidariedade partilhada entre seus irmãos. "Essa mudança de conduta foi fruto do encontro concreto com Jesus, sem o qual os discípulos haviam permanecido assim como estavam"2. A pergunta que move Schillebeeckx em sua pesquisa é a seguinte: o que se encontra na raiz da experiência feita pelos discípulos? E o que, de fato, os motivou a fazer tal experiência? Por meio de um longo percurso de reflexão nosso autor chega a afirmar que, para reconhecer Jesus como o vivente, os discípulos tiveram que passar por uma experiência de conversão.

Ao dizer que privilegiaremos a cristologia narrativa desenvolvida pelo autor, devemos explicar que a pesquisa cristológica de Schillebeeckx se diferencia do método tradicional, mas não se opõe à reflexão dogmática. Para Schillebeeckx, a história dos dogmas se desenrola numa perspectiva de interpretação da própria história de Jesus de Nazaré, portanto, tem significado para a fé, mas não pode ser o único caminho que determina o rumo da reflexão cristológica. Comungamos da posição, pois a reflexão cristológica deve partir da própria história de Jesus, ou seja, da experiência salvífica originária, que é a fonte primária de toda e qualquer interpretação.

\section{O PROJETO CRISTOLÓGICO DE EDWARD SCHILLEBEECKX}

Antes de abordar a cristologia de Schillebeeckx, elencaremos as principais obras que condensam sua reflexão. Seu pensamento cristológico concentra-se em três densos volumes: Jesus, história de um vivente; Cristo e os cristãos e História humana, revelação de Deus, sendo que as duas primeiras obras monumentais oferecem as bases de sua reflexão cristológica. No entanto, ele os descreve como prolegômenos para uma cristologia, afirmando que estes escritos não passam de um ensaio cristológico ${ }^{3}$. Porém, esta denominação não reduz sua reflexão, mas lhe confere o status de uma cristologia em construção ${ }^{4}$. Não obstante, também observa que os prolegômenos de uma reflexão cristológica futura podem ser historicamente mais importantes que certas cristologias que se dizem acabadas e que se contentam em apresentar suas sínteses prontas, sem possibilidade de abertura ${ }^{5}$. "Uma cristologia que pretende ser fiel a Jesus e ao Evangelho só pode ser construída por etapas e estar situada histórica e geograficamente". Caso contrário, perde-se todo o significado para o ser humano.

\footnotetext{
SCHILLEBEECKX, Edward. La questione cristologica, p. 17.

2 SCHILLEBEECKX, Edward. En torno al problema de Jesús, p. 23.

${ }^{3}$ Cf. SCHILLEBEECKX, Edward. Jesús, la historia de un viviente, p. 29; SCHILLEBEECKX, Edward. Cristo y los cristianos, p. 18.

${ }^{4}$ Cf. SCHILLEBEECKX, Edward. Jesús, la historia de un viviente, p. 646; SCHILLEBEECKX, Cristo y los cristianos, p. 843. As duas obras citadas, suscitaram reações por parte de críticos, o que levou o autor escrever um volume complementário que em espanhol traz o título En torno al problema de Jesús. Claves de una cristología, onde explica seus pontos de vista e dialoga com os críticos de sua obra.

${ }^{5}$ Cf. SCHILLEBEECKX, Edward. Cristo y los cristianos, p. 843.

${ }^{6}$ SCHILLEBEECKX, Edward. Cristo y los cristianos, p. 18.
} 
O terceiro volume, História humana: revelação de Deus, anunciado como sendo uma reflexão cristológica, é muito mais marcado por questões de eclesiologia ${ }^{7}$. Dessa forma, nosso autor aprofunda a relação existente entre a Igreja, a cristologia e a pneumatologia. De fato, os cristãos só encontram Deus em Jesus, confessado como o Cristo. Sendo esta uma confissão da Igreja como comunidade do Espírito, é correto afirmar que a cristologia é mediada pela eclesiologia que, por sua vez, move-se pelo próprio Espírito. Portanto, da mesma forma que não é possível falar de Deus como cristão sem a cristologia, também é impossível falar de cristologia sem a pneumatologia. Assim, torna-se evidente que tanto a cristologia como a pneumatologia só podem ser entendidas dentro da comunidade eclesial.

Vale ressaltar que a reflexão cristológica de Schillebeeckx traçada nas três obras citadas anteriormente tem uma impostação diferente da cristologia tradicional e clássica, pois está voltada para os aspectos práticos e pastorais na esperança de que o contato com Jesus suscite uma nova práxis de vida no seio da comunidade cristã atual. Nosso teólogo entende que a reflexão sobre Jesus deve ser feita em consonância com os textos da Sagrada Escritura, mas a interpretação da Escritura não pode ser feita a partir dos dogmas. Ao contrário, é a própria história dos dogmas que deve partir de uma busca histórica de Jesus ${ }^{8}$. Schillebeeckx faz um percurso hermenêutico que lhe permite passar das interpretações de fé que se encontram no Novo Testamento para as experiências históricas geradas por tais interpretações. Nosso autor desenvolve essa reflexão a partir de dois aspectos: a) o primeiro diz respeito ao encontro que os discípulos tiveram com Jesus antes da Páscoa e à luz das expectativas messiânicas chegaram a interpretá-lo como o "profeta escatológico" de Deus. Porém, ao mesmo tempo em que há uma continuidade da crença, dentro de um horizonte cultural da expectativa messiânica, também percebemos uma descontinuidade em relação a Jesus. Sua vida histórica desmentiu estas expectativas abrindo aos discípulos uma nova experiência religiosa e provocando neles uma mudança de vida; b) o segundo aspecto da reflexão passa pela busca de mostrar a experiência de fé das primeiras comunidades depois da Páscoa, experiência que permitiu aos discípulos reconhecerem a presença do ressuscitado no meio deles, conduzindo-os à compreensão de sua pessoa. Essa experiência torna-se a base para todas as gerações que não poderão mais se encontrar diretamente com o homem Jesus, mas que se sentem em continuidade com a sua práxis histórica e vivem segundo o seu Espírito.

\section{A CRISTOLOGIA NARRATIVA}

Já anunciamos que a reflexão de Schillebeeckx se desvincula do modo tradicional de fazer cristologia e busca recuperar a história de Jesus, acreditando que este trabalho de reconstrução histórica pode soar como um convite a uma opção de vida para o cristão contemporâneo. Além de fazer a narrativa, ajudado por uma excelente base bíblica, da vida histórica de Jesus, o autor examina as origens da fé neotestamentária e busca refazer, com o leitor atual, o itinerarium mentis percorrido pelos discípulos de Jesus desde o batismo no Jordão até o pós-morte, onde o confessaram como o Filho de Deus.

\footnotetext{
${ }^{7}$ Cf. SCHILLEBEECKX, Edward. Los hombres relato de Dios, p. 7.

${ }^{8}$ Cf. SCHILLEBEECKX, Edward. Jesús, la historia de un viviente, p. 31. Schillebeeckx afirma que fazer teologia com uma base realmente bíblica é uma tarefa árdua - processo que certamente vai derrubando expectativas e sínteses prontas. A própria síntese está sempre em construção-movimento. Esse pensamento vem de encontro com o que dissemos antes a respeito do fundamento da cristologia do autor, que está fundada sobre a história de Jesus e não sobre reflexões realizadas ao longo da Tradição. Sem excluir tais reflexões e reconhecendo que elas foram formando as colunas do cristianismo na história, acolhemos a tese do nosso autor que nosso ponto de partida deve ser o próprio Jesus de Nazaré.
} 
Schillebeeckx acredita o cristão atual, seguindo este relato, possa como em Emaús, dizer: "Não ardia o nosso coração enquanto conversava pelo caminho?" (Lc 24,32)".

Porém, a reconstrução histórica realizada por Schillebeeckx acontece dentro de uma dinâmica narrativa e não a partir da história factual, de "acontecimentos verdadeiros", científicos. Ao anunciar que na exposição de sua cristologia ele tomará o caminho da narrativa, Schillebeeckx explica que está de acordo com a perspectiva bíblica, em que a história toma uma dimensão diferenciada da abordagem científica. A Bíblia se preocupa em contar a história transmitindo-a e atualizando-a. "Nisso, a facticidade histórica, ou seja, a questão se isso ou aquilo aconteceu exatamente assim, não tem tanta importância"10. O mais importante é a verdade que emerge da própria narrativa, isto é, o ponto crucial é se essa narrativa nos impulsiona e nos torna sujeitos ativos de uma nova narrativa.

Devemos ter presente que, ao descrever os fatos, a Bíblia apresenta "liberdade histórica", próprio do estilo utilizado neste período. Assim, a maneira como os personagens se comportam, os atos concretos que o autor lhes atribui e a maneira como são apresentados a partir da história bíblica, são comentários indiretos sobre os personagens que fazem parte de sua narrativa. Eis a opinião de Schillebeeckx a esse respeito:

Do ponto de vista da historiografia moderna, os atos descritos podem ser historicamente autênticos ou fictícios (com ou sem núcleo histórico) - isso não importa. Porém, mostram exatamente como o autor, a serviço de seus leitores, vê aquelas pessoas, e como se apresentam a ele, que tem sempre a intenção de levar os leitores a praticar o bem e afastar-se do $\mathrm{mal}^{11}$.

A interpretação teológica de Jesus não é alheia à sua atuação durante os dias nesta terra, e isso, segundo o autor, impressionou as pessoas de tal maneira que fizeram a leitura de sua vida e a narraram em profunda consonância com sua realidade histórica. Schillebeeckx também lembra que essa concepção não anula a pergunta pelo Jesus histórico, porém não pode se tornar uma obsessão positivista.

\section{A CONVIVÊNCIA PRÉ-PASCAL DOS DISCÍPULOS COM JESUS}

Outro aspecto que nos permite acompanhar a análise de Schillebeeckx sobre a práxis de Jesus é sua convivência próxima com o círculo mais íntimo dos diversos discípulos que responderam ao chamado do seguimento. Os Evangelhos narram que Jesus mesmo chamou e enviou os discípulos em missão e tais narrativas procedem das tradições de Marcos e da fonte $Q$, que devem ser as mais antigas. A primeira tradição se encontra em $L c$ 9,1-6; 10,2-12; Mt 9,37-38; Mt 10,7-16; a segunda, em $M c$ 6,7-13. O núcleo historicamente rigoroso dessa narrativa remonta aos dias da vida terrena de Jesus, embora alguns detalhes tivessem sido modificados por necessidade de situações da Igreja após a Páscoa. Contudo, a missão pré-pascal continuou a servir de norma e critério para esse anúncio realizado após a Páscoa.

O que sobressai desses relatos é o fato de que "ser discípulo de Jesus" se baseia na vocação que emana do próprio Jesus, e é instrutivo perceber como os discípulos

\footnotetext{
${ }^{9}$ SCHILLEBEECKX, Edward. Jesús, la historia de un viviente, p. 45-6. Schillebeeckx entende que uma cristologia narrativa não dá muita importância à faticidade histórica, isto é, à questão de que algo aconteceu desta ou de outra maneira; o mais importante é perceber se a história diz algo e afeta os homens e as mulheres de hoje, fazendo-os sujeitos ativos de uma nova história.

${ }^{10}$ SCHILLEBEECKX, Edward. Jesús, la historia de un viviente, p. 69.

${ }^{11}$ SCHILLEBEECKX, Edward. Jesús, la historia de un viviente, p. 70.
} 
dizem ter sentido a força que provém dessa vocação. Schillebeeckx destaca dois grupos de discípulos, acentuando que antes de Jesus instituir os Doze (Mc 3,13-15), já havia discípulos seguindo-o (Mc 1,16-20; 2,14; 2,15; 3,7). Desse modo, o autor distingue entre a "vocação de discípulos" e a "constituição dos doze", escolhidos no meio deles. A escolha da constituição dos Doze é apresentada como uma "vocação fundamental" e, citando $M t$ 11,29, Schillebeckx diz que existe um diferencial entre "chamado dos discípulos" e "chamado dos Doze": "os Doze recebem o convite para aprender com Jesus" 12 . Assim, as palavras de Jesus ressoam como uma didaqué, uma instrução para a sua comunidade.

Os Evangelhos apresentam a vocação que vem de Jesus seguindo sempre o mesmo esquema, pois se trata de uma construção literária. Eis a estrutura bem organizada que emerge da reflexão do autor: a) Jesus que passa $(M c 1,16.19 ; 2,14)$; vê alguém (Mc 1,16.19; Jo 1,47); c) conta qual é a profissão da pessoa $(M c 1,16.19 ; 2,14 ; L c 5,2)$; d) a vocação em si $\left(M c 1,17.20 ; 2,14 ; J_{o} 1,37\right)$; e) quem é chamado abandona tudo (Mc 1,18.20; menos em $M c$ 2,14, mas sim em $L c 5,11.28$ ); f) a pessoa chamada segue Jesus $(M c 1,18.20 ; 2,14 ; L c 5,11)$. Depois de aderirem ao chamado, os discípulos seguem Jesus fazendo o que Ele faz: anunciam a mensagem do Reino, curam os enfermos e expulsam os demônios. O chamado de Jesus para segui-lo expressa com clareza a sua atividade de profeta escatológico da iminente soberania de Deus. Portanto, os discípulos entenderam desde cedo que seguir Jesus era colocar-se incondicionalmente a serviço do Reino de Deus e também "mostrar, em reconhecimento de sua missão profética, a fé em Deus e a fé no Reino de Deus, cumprindo para isso a metanoia requerida pelo Reino"13.

Nos contatos pessoais e passageiros com Jesus, da parte de quem visava alguma cura, já havia ao mesmo tempo um reconhecimento de Jesus como profeta vindo de Deus. Mas apenas a convivência habitual de seus discípulos íntimos que o acompanhavam (embora às vezes com pouca fé) é o modelo pré-pascal do que a vida cristã deverá ser depois da Páscoa ${ }^{14}$.

À luz da práxis do Reino vivida por Jesus, os discípulos que se colocaram ao seu lado experimentaram a presença gratuita de Deus que os chamou a uma mudança de vida, levando-os ao discernimento sobre suas próprias opções. Schillebeeckx afirma que o encontro com Jesus incita a pessoa a se perguntar se ela não se encontra imersa "numa situação de pecado, num estado de injustiça ou numa pobreza de tipo estrutural"15. De fato, a proximidade gratuita de Deus não foi experimentada de forma "alheia ou acima da história social, política e econômica"16 , pois Schillebeeckx não concebe a fé cristã desligada da dinâmica social. Quem quer se colocar nas pegadas de Jesus deve questionar uma conjuntura que continua oprimindo e sufocando os pobres.

Enfim, o encontro com Jesus ainda hoje interpela o homem e a mulher a dar uma reposta pessoal a respeito do sentido de sua existência e a traduzir essa resposta numa práxis de vida consequente. Diante do anúncio do Reino é impossível não tomar posição pois, mesmo que alguém não explicite opções, sua práxis o revelará. Porém, a resposta aos apelos do Reino não se baseia em teorias, é o que nos alerta o Documento de Aparecida, ainda tão recente em nosso meio. A resposta à fé é fruto da obra divina, também quando essa resposta é expressa nos projetos humanos, diante das causas

\footnotetext{
${ }^{12}$ SCHILLEBEECKX, Edward. Jesús, la historia de un viviente, p. 216.

${ }^{13}$ SCHILLEBEECKX, Edward. Jesús, la historia de un viviente, p. 231.

${ }^{14}$ SCHILLEBEECKX, Edward. Jesús, la historia de un viviente, p. 221.

${ }^{15}$ SCHILLEBEECKX, Edward. Los hombres relato de Dios, p. 155.

${ }^{16}$ SCHILLEBEECKX, Edward. La disposiozine del Vangelo di pace, p. 149.
} 
sociais. Por ser obra divina, a vida nova que nasce do seguimento é um caminho aberto, por meio do qual o Reino de Deus vai se manifestando pouco a pouco, até sua consumação futura.

Seguiremos apresentando a concepção do autor sobre a experiência pascal originária, realizada pelos discípulos de Jesus.

\section{A RECONSTRUÇÃO DA EXPERIÊNCIA PASCAL ORIGINÁRIA: A "EXPERIÊNCIA DE CONVERSÃO" VIVIDA PELOS DISCÍPULOS}

Na tentativa de reconstruir a experiência pascal originária, vivida pelos discípulos, a reflexão de Schillebeeckx se movimenta entre dois polos: o primeiro se refere ao abandono de Jesus por parte dos discípulos; o segundo polo diz respeito à reunificação dos discípulos depois da experiência pascal. Portanto, existem duas realidades concretas desde os primórdios e confirmadas historicamente pela tradição: de um lado, os discípulos, abandonando aquele que os unia, Jesus de Nazaré. De outro, eles estão reunidos novamente em nome de Jesus, proclamando corajosamente sua ressurreição e confessando-o como Cristo, Filho de Deus e Senhor. Eis a pergunta que emerge claramente de seu texto:

Que fatos concretos levaram os discípulos, depois da morte de Jesus, a proclamar que Ele vive realmente? Se não pode ser a ressurreição como tal, nem o sepulcro vazio, tampouco as aparições - dados que pressupõem a ressurreição - que fatos ocorreram? ${ }^{17}$

A tese central de Schillebeeckx, que afirma a experiência de conversão, gira ao redor dessa provocação: para ele há de ter acontecido alguma coisa de cunho histórico entre a morte de Jesus e a proclamação da fé, para que os discípulos, de fato, experimentassem a ressurreição. Segundo ele, esse fato foi a "experiência de conversão".

Neste sentido, na tentativa de elucidar a resposta à pergunta sobre o que deve ter acontecido entre a morte e o anúncio da ressurreição de Jesus, nosso autor entende que a resposta não pode ser a ressurreição em si mesma, pois apesar de ser um acontecimento real, ela não faz parte da história humana ${ }^{18}$. O fator que moveu os discípulos desde a fuga, enquanto expressão de pouca fé e ruptura no seguimento, até a proclamação de Jesus como o Cristo só pode ter sido a experiência do perdão ${ }^{19}$. O fato de se sentirem perdoados por Jesus, além de condição fundamental para o processo de conversão, também evidenciou que Jesus estava vivo. Certamente um morto não poderia conceder nenhum perdão ${ }^{20}$.

\footnotetext{
${ }^{17}$ SCHILLEBEECKX, Edward. Jesús, la historia de un viviente, p. 352.

${ }^{18} \mathrm{Cf}$. SCHILLEBEECKX, Edward. Jesús, la historia de un viviente, p. 304-350.

${ }^{19}$ Cf. SCHILLEBEECKX, Edward. Jesús, la historia de un viviente, p. 353. Em se tratando da conversão paulina, os relatos de Damasco (At 9; 22; 26) pretendem mostrar a maneira como Deus se manifesta na vida de Paulo como epifania divina por meio de Jesus Cristo. Em At 9 , o acento está na nova identidade que se desvela na vida de Paulo, a de ser um defensor de Cristo. No relato de At 26, além da conversão, aparece a dimensão da missão, pois Paulo é enviado a curar a cegueira dos pagãos. No capítulo 22, a visão de conversão é usada para justificar a missão apostólica de Paulo a todos os povos: é o relato de um homem que viu Jesus como luz dos pagãos.

${ }^{20} \mathrm{Cf}$. SCHILLEBEECKX, Edward. Jesús, la historia de un viviente, p. 362. É importante sublinhar que Schillebeeckx busca fundamentação para estas constatações nos relatos neotestamentários que, segundo ele, estão profundamente relacionados com o dom do perdão dos pecados (Jo 20,22s; Lc 24,47; Mt 28,19; At 26,18; 1 Cor 15,17; Rm 4,25). A partir desses textos, ele assume a proximidade e a relação entre "ressurreição e perdão dos pecados". Assim, afirma que o Evangelho de João se encerra com uma aparição de Jesus, com estas palavras: "a quem lhes perdoardes os pecados, lhes serão perdoados" (Jo 20,22-23). O serviço da reconciliação (2 Cor 5,18) é mencionado a propósito do batismo cristão em todos os relatos de aparições oficiais ( Lc 24,47; Mt 28,19; Jo 20,23). Os discípulos pregam o perdão dos pecados (Lc 24,47; At 26); Paulo diz "Se Cristo não ressuscitou, seguis com vossos pecados" (1 Cor 15,17-18), e, em outra passagem, "ressuscitou para a nossa justificação" (Rm 4,25). Portanto, Schillebeeckx conclui que o perdão dos pecados vai junto do nome de Jesus (At 5,31; $10,43 ; 26,18)$.
} 
Daí emerge um dado fundamental na análise cristológica de Schillebeeckx: a experiência humana que abre a possibilidade da fé na ressurreição não pode ser baseada no sepulcro vazio, mas na conversão dos discípulos e no nascimento da comunidade, como "comunidade de Deus" 21 . Deste modo, nosso autor evita qualquer forma de objetivismo e estabelece uma circularidade entre a fé que os discípulos possuem no ressuscitado e a práxis do Reino de Deus vivida nas primeiras comunidades cristãs. De um lado, a convicção de que Jesus continua presente entre os seus, encoraja as comunidades e as impulsiona a continuar solidárias com os pobres e marginalizados; de outro, nosso autor entende que é justamente essa prática ligada à memória de Jesus que possibilita aos discípulos a experiência de salvação, por meio da qual eles podem reconhecer a ressurreição ${ }^{22}$. Esta circularidade não deve levar à afirmação de que não exista uma base objetiva para a ressurreição. Por ser um acontecimento meta-histórico, a ressurreição foge da acessibilidade direta dos discípulos:

A ressurreição é um acontecimento real, cumprido em Jesus por Deus, mas, em si mesmo, é um acontecimento que vai além dos limites da morte; e os discípulos, evidentemente, não tiveram acesso a este acontecimento metahistórico e escatológico. Diferente de alguns apócrifos, o Novo Testamento não traz nenhuma informação sobre a realidade da ressurreição como tal ${ }^{23}$.

Evidentemente a experiência de conversão vivida pelos discípulos não aconteceu de forma mágica, mas exigiu deles um longo caminho de amadurecimento até que chegassem à fé: depois da morte de Jesus, os discípulos recordaram a convivência que tiveram com ele, sua atividade, o anúncio do Reino de Deus e do próprio Deus como misericórdia e perdão e as recordações de sua despedida. Esta anamnese da vida de Jesus é essencial no processo de conversão dos discípulos que, embora tivessem fraquejado, não haviam abandonado totalmente a fé.

No entanto, mesmo assumindo que a experiência pascal esteja fortemente ligada à experiência anterior vivida pelos discípulos juntamente com Jesus, nosso autor observa uma novidade notável na relação com o ressuscitado. Esta nova relação implica o "evento salvífico", que foi sentido como pura graça de Deus e resultou na confissão cristológica do crucificado-ressuscitado. "O fundamento da fé é inegavelmente Jesus de Nazaré na sua oferta terrena de salvação renovada e depois de sua morte pela graça do ressuscitado" ${ }^{24}$. Fica evidente que a experiência pascal se fundamenta na ação do próprio Deus que agiu em Jesus, ressuscitando-o, e não na experiência dos discípulos, que, na verdade, foi uma experiência do que aconteceu com Jesus.

Mais uma vez sublinhamos a primazia da experiência de fé, responsável por trazer à luz o acontecimento da ressurreição, que sem ela permaneceria oculto no mistério de Deus. Desse modo, podemos afirmar o "paradoxo" presente na experiência da ressurreição: nela encontram-se, de um lado, a perspectiva humana, e de outro, a oferta divina, já que a experiência cristã de fé é obra do Espírito Santo e não obscura magia. Para o nosso autor, "a experiência pascal consiste no fato experienciado de que os discípulos se reuniram novamente, não apenas em nome de Cristo, mas pela força de Cristo" 25 .

\footnotetext{
${ }^{21}$ SCHILLEBEECKX, Edward. Perché la politica non è tutto, p. 39.

${ }^{22}$ Cf. SCHILLEBEECKX, Edward. La questione cristologica, p. 98.

${ }^{23}$ SCHILLEBEECKX, Edward. Jesús, la historia de un viviente, p. 354; SCHILLEBEECKX, Edward. La questione cristologica, p. 97-98.

${ }^{24}$ SCHILLEBEECKX, Edward. Jesús, la historia de un viviente, p. 411.

${ }^{25}$ SCHILLEBEECKX, Edward. Jesús, la historia de un viviente, p. 642.
} 
A análise da ressurreição se insere nesta mesma dinâmica. A experiência e a interpretação acontecem simultaneamente, pois a pessoa que experimenta permanece ativa ante qualquer acontecimento. Também se torna necessário lembrar que a experiência se realiza em um contexto social e no interior de um "horizonte interpretativo" que influencia a sua interpretação. Por isso o autor propõe sempre uma tomada de posição para conhecer melhor a "autoridade das experiências". Dito isso, sublinhamos que o aspecto objetivo da fé se manifesta na dinâmica humana subjetiva. Embora os dois aspectos não se confundam, são inseparáveis. "A ressurreição de Jesus, ainda que não se identifique com a experiência pascal ou com a experiência de fé dos discípulos [...], não é separável dela" ${ }^{26}$.

Nosso autor, portanto, assegura uma posição equilibrada, afastando-se tanto de um subjetivismo, que percebe a ressurreição somente como uma experiência de fé, quanto de um objetivismo unilateral, que a vê como um dado histórico empiricamente comprovado ${ }^{27}$. E, ao distanciar-se da hipótese de identificação entre "acontecimento da ressurreição" e "experiência de fé", se mantém de acordo com a fé neotestamentária. O Novo Testamento testemunha que a fé em Jesus provém da graça e da revelação de Deus, mas que é mediada pelos processos psíquicos e cognitivos, próprios do ser humano ${ }^{28}$. Não obstante, alguns autores não lhe pouparam severas críticas, acusando-o de conceber a ressurreição somente a partir da experiência dos discípulos.

\section{A CRISTOLOGIA DE SCHILLEBEECKX A SERVIÇO DA EXPERIÊNCIA DA FÉ EM TEMPOS ATUAIS}

A cristologia de Schillebeeckx se desenvolve em três linhas arquitetônicas: a primeira se preocupa em mostrar a mensagem de Jesus e a práxis de sua vida; a segunda se interessa em apresentar como estes acontecimentos foram experimentados naquela época, enquanto salvação para as pessoas; a terceira diz respeito à possibilidade da articulação da fé cristã no mundo contemporâneo.

A terceira linha arquitetônica, relativa à dinâmica do "crer hoje", isto é, a que se refere à preocupação do autor em mostrar a pertinência da fé cristã para os dias de hoje, se impõe em todos os seus escritos, assinalando seu compromisso com a teologia e com a práxis da fé cristã. Desse modo, emerge a pergunta de como podemos experimentar, nos dias de hoje, a salvação em Jesus Cristo, por meio de um encontro significativo e libertador com Ele. Para o autor, o cristão é chamado a reconhecer a universalidade da salvação em Jesus e isso deve soar como um convite para que ainda hoje as pessoas reconheçam o Deus salvador, por excelência, em Jesus de Nazaré29.

A busca da ressignificação da fé cristã em tempos atuais levou o teólogo belga a demonstrar, do ponto de vista histórico, os dados fundamentais da vida de Jesus que puseram seus contemporâneos diante de uma situação de revelação (disclosure situation), apontando para uma particular ação salvífica de Deus nele. Essa descoberta fez com que eles chegassem à conclusão que em Jesus se revela a verdadeira face de Deus e, simultaneamente, algo de definitivo e decisivo para suas vidas ${ }^{30}$. De fato, o

\footnotetext{
${ }^{26}$ SCHILLEBEECKX, Edward. Jesús, la historia de un viviente, p. 605-606.

${ }^{27}$ Cf. SCHILLEBEECKX, Edward. Jesús, la historia de un viviente, p. 604-5; SCHILLEBEECKX, Edward. La questione cristologica, p. 98-99. Schillebeeckx declara não se identificar com as interpretações de Marxsen e Bultmann, que tendem a identificar a ressurreição de Jesus com a renovação da vida e da fé dos discípulos depois de sua morte. Essa posição não deixa claro se Jesus ressuscitou pessoalmente, se segue vivendo entre nós de uma forma nova e se realiza por sua própria virtude essa renovação de vida nos discípulos.

${ }^{28} \mathrm{Cf}$. SCHILLEBEECKX, Edward. Jesús, la historia de un viviente, p. 605; SCHILLEBEECKX, Edward. La questione cristologica, p. 96.

${ }^{29}$ Tal significado único e universal só pode ser respondido com base na fé. Contudo, por mais que não possam ser historicamente demonstradas, as afirmações de fé sobre uma determinada realidade necessitam fundar-se nesta realidade para que não se tornem ideologia.

${ }^{30} \mathrm{Cf}$. SCHILLEBEECKX, Edward. L'approcio a Gesù di Nazaret, p. 57.
} 
caráter único e universal de Cristo já vem atestado no Novo Testamento: "Nenhum outro pode proporcionar a salvação; não há outro nome sob o céu, concebido aos homens, que possa salvar-nos" $(A t 4,12)$; "Há somente um Deus, há somente um mediador, o homem Cristo Jesus" (1 Tm 2,5); "Eu sou o caminho, a verdade e a vida: ninguém vai ao Pai se não por mim"( $\left.J_{o} 14,6\right)$. Poderíamos ainda citar outros textos bíblicos onde aparece o caráter salvífico de Jesus Cristo, no entanto, os textos citados acima são suficientes para apoiar a opinião de Schillebeeckx sobre a unicidade salvífica de Cristo.

Esta análise da reflexão schileebeckxiana a respeito da unicidade e universalidade de Jesus Cristo nos leva a tomar consciência de que devemos agir com cautela para evitar a absolutização do cristianismo diante de outras religiões. Esta atitude não condiz com a realidade cristã e nem com a proposta do diálogo inter-religioso muito presente no cenário atual da teologia e das ciências da religião. No entanto, da mesma forma, não é condizente com a identidade cristã assumir um indiferentismo anulador de diferenças e criador de igualdade diante das religiões. Neste sentido, o teólogo belga esclarece que a posição cristã mais honesta diante do diálogo com outras religiões é a afirmação convicta de que em Jesus Deus se revelou de modo definitivo e irreversível em nossa história.

Com base no que foi exposto até aqui, é importante esclarecer que Schillebeeckx não se preocupa em desenvolver uma reflexão a partir do diálogo inter-religioso, o que seria problemático para a sua exposição. Sua intenção recai na explicitação da identidade cristã que vai sendo tematizada a partir do enfoque soteriológico da cristologia. O fio de ouro que tece tal reflexão é o esclarecimento do cristianismo enquanto tematização de uma experiência salvífica e única, que pode ser realizada em cada época da história.

Assim, Schillebeeckx sublinha que na origem do cristianismo houve uma experiência salvífica de encontro com Jesus, realizada por alguns homens e mulheres, que foi geradora do Novo Testamento, pois "cada escrito neotestamentário trata da salvação experimentada em e através de Jesus" ${ }^{31}$. Na visão schillebeeckxiana, o Novo Testamento tem um valor normativo permanente para a fé cristã, porém, não como depósito de verdades eternas e imutáveis, mas enquanto testemunho dessa experiência salvífica vivida por homens e mulheres junto com Jesus, suscitando a confissão de que Ele é o Cristo ${ }^{32}$.

É através do Novo Testamento que temos acesso ao movimento cristão que em Jesus tomou impulso. Deste modo, fica claro que, para o autor, a origem do cristianismo não é nem só Jesus e nem somente a comunidade cristã. Dito de outro modo, o ponto de partida do cristianismo não é simplesmente Jesus de Nazaré e nem só o querigma ou o credo eclesiástico, ele se funda sobre as duas afirmações em conjunto, como oferta e como resposta: "o ponto de partida é a primeira comunidade cristã, sim, mas como reflexo, isto é, espelhando-se naquilo que o próprio Jesus foi, falou e fez" ${ }^{33}$. Schillebeeckx insiste que a experiência originária que resultou na formação das comunidades cristãs e conservou-se no testemunho neotestamentário permanece como um valor normativo para toda a resposta de fé posterior ${ }^{34}$.

No entanto, para que "a história cristã de experiências" continue, a mensagem transmitida deve ser compreensível e convincente também para o homem e a mulher

\footnotetext{
${ }^{31}$ SCHILLEBEECKX, Edward. Esperienza umana e fede in Gesù Cristo, p. 26. O autor explicita que o Novo Testamento se sente livre em falar da primeira experiência salvífica feita com Jesus, usando conceitos diferenciados, porque o objetivo é unicamente exprimir o acontecido com Jesus. Essa realidade nos confere liberdade para também expressar a experiência salvífica que fazemos com Ele, de modo novo, traduzindo-a em cifras colhidas em nossa cultura contemporânea, que traz seus próprios problemas e necessidades. Enfim, a atualização da primitiva experiência cristã ressoa como condição necessária para permanecermos fiéis ao que os primeiros cristãos experimentaram como salvação em Jesus. Se não o fazemos, a experiência será confinada nos limites da história, sem força de expressão.

${ }^{32} \mathrm{Cf}$. SCHILLEBEEECKX., Edward. La questione cristologica, p. 31.

${ }^{33}$ SCHILLEBEEECKX, Edward. Jesús la historia de un viviente, p. 38; SCHILLEBEEECKX, Edward. L'aproccio a Gesù di Nazaret, p. 23. ${ }^{34} \mathrm{Cf}$. SCHILLEBEEECKX., Edward. Jesús la historia de un viviente, p. 51-53.
} 
de hoje, pois eles não aceitam essa mensagem somente em função de uma autoridade institucional que dela faz a mediação. A experiência religiosa deve inserir-se no contexto das experiências humanas seculares para se tornar convicção e experiência pessoal. Deste modo, a mensagem da tradição deve ser proposta numa "catequese de experiência" para poder ser experimentada como "resposta de libertação" às perguntas vitais que o ser humano põe no mundo contemporâneo.

\section{CONCLUSÃO}

Ao expor neste artigo os traços da cristologia schillebeeckxiana, nosso intuito foi o de considerar a categoria da experiência como pano de fundo da abordagem, já que a experiência constitui o instrumental teórico de interpretação para a reflexão cristológica do autor. Na esteira de Schillebeeckx, ressaltamos que, ao longo da experiência pascal, os discípulos foram compreendendo que, na ressurreição, Deus acolheu a pessoa, a mensagem e todo o caminho de vida de Jesus, marcado somente pelo bem (cf. At 10,38). Esta certeza os levou a confiar que "o Pai o acolheu e imprimiu-lhe o seu selo, contradizendo o que os homens fizeram a Ele" ${ }^{35}$. Tal experiência também ajudou os discípulos a reconhecerem de forma mais clara o significado da pregação e da prática do Reino de Deus realizadas por Jesus. Antes da Páscoa, mesmo sem possuir a fé em Jesus, os discípulos já o percebiam como o portador de uma mensagem divina. Porém, foi somente após a Páscoa que se evidenciou o que já haviam percebido na convivência com Ele e, assim, entenderam que nele se cumpriram suas expectativas de salvação. Podemos afirmar que há uma continuidade na descontinuidade no tocante à fé pré-pascal dos discípulos: há uma continuidade na confiança e na adesão pré-pascal, porém, há uma novidade porque agora a fé é um crer em Jesus como o Cristo ${ }^{36}$.

Após a morte de Jesus, um fator importante que levou os discípulos a retomarem o caminho do discipulado foi a memória da convivência anterior que tiveram com Ele - o objeto desta recordação era sua vida e mensagem. Esses momentos de lembrança são elementos essenciais no processo de conversão dos discípulos. Essenciais, mas não únicos, pois, juntamente com o exercício da memória de Jesus se acentua uma experiência nova e de importância capital: os discípulos experimentam o perdão de sua pouca fé e vivenciam uma renovação de vida, através da oferta de salvação, proveniente do próprio ressuscitado. Eles tomam consciência que, apesar de sua fraqueza, continuam nas mãos misericordiosas de Deus.

Juntamente com esta experiência de perdão, acontece a experiência reveladora, que abre os olhos dos discípulos para o acontecido com Jesus: a experiência pessoal de uma existência nova implica a certeza de fé que Jesus está vivo. Em síntese, o perdão da covardia e da pouca fé dos discípulos é a experiência que, iluminada pela recordação de sua vida terrena, torna-se a matriz onde nasce a fé em Jesus, enquanto ressuscitado.

A intenção de Schillebeeckx, ao apresentar uma cristologia narrativa foi a de fomentar o seguimento a Jesus no contexto de fé atual. Este método levou a reflexão a preocupar-se com o itinerário humano de Jesus e ajudar a libertar a própria fé cristã da tentação de desfiguração. É missão da teologia refletir sobre o núcleo da existência cristã, favorecendo uma orientação sobre o que dizer hoje aos homens e às mulheres do nosso tempo, já encharcados de palavras, nem sempre cristãs, por todos os cantos da vida.

${ }^{35}$ SCHILLEBEEECKX., Edward. Los hombres relato de Dios, p. 172.

${ }^{36}$ Cf. SCHILLEBEEECKX., Edward. Jesús, la historia de un viviente, p. 180-181. 


\section{REFERÊNCIAS}

SCHILLEBEECKX, Edward. Jesús, la historia de un viviente. Madrid: Cristiandad, 1983. . Cristo y los cristianos: gracia y liberación. Madrid: Cristiandad, 1982. . Los hombres relato de Dios. Salamanca: Sígueme, 1994. . La questione cristologica: un bilancio. Brescia: Queriniana, 1985. . L'approcio a Gesù di Nazaret: linee metodologiche. Brescia: Queriniana, 1972. 1987. Perché la política non è tutto. Parlare di Dio in un mondo minacciato. Brescia: Queriniana, En torno al problema de Jesús: Claves de una cristologia. Madrid: Cristiandad, 1993. . La disposiozine del Vangelo di pace. Concilium, Roma, v. 19, n. 4, p. 144-59, 1983.

Recebido em: 07/11/2018 Aprovado em: 03/12/2018

\section{Correspondência para:}

Prof ${ }^{\mathrm{a}} \mathrm{Dr}^{\mathrm{a}}$ Valdete Guimarães

Faculdade Diocesana São José (FADISI)

Av. Getúlio Vargas, 3030 - Vila Ivonete

CEP: 69908-650 Rio Branco, AC, Brasil 